\title{
ARTIGOS
}

\section{Por onde circulam os corpos invisíveis? Intersecções entre população em situação de rua e gêneros dissidentes no acesso institucional urbano}

\author{
Nathália Carneiro da Cunha Prados ${ }^{1}$ \\ Brune Coelho Brandão \\ Juliana Perucchi ${ }^{3}$
}

Resumo: No Brasil, historicamente a população negra e indígena sofreu violências que as colocaram em uma posição de subalternidade, de modo a produzir diferentes posições de sujeitos de (sem) direitos. Nos diais atuais, esse processo histórico, político e social possibilitou, através da noção de direito neoliberal no país durante o período de redemocratização, que essas pessoas historicamente a margem ocupassem uma nova posição de sujeito - a de população em situação de rua. Além disso, o Brasil é o país que apresenta grande índice de violência contra a população travesti e transexual. Desse modo, esse trabalho, com base na perspectiva interseccional feminista, busca uma articulação entre os marcadores sociais de classe, raça e gênero, de modo a problematizar as limitações dos acessos institucionais que pessoas travestis e transexuais em situação de rua vivenciam no município. Realizou-se uma observação flutuante, consoante com os pressupostos da etnografia, nas instituições em que tais sujeitos circulavam na cidade. Através disso, foi elaborado um diário de campo com impressões e falas, analisados sob a ótica metodológica da análise do discurso de Foucault. Como resultado, pode-se destacar o papel normatizador e repressor da polícia em reiterar

\footnotetext{
${ }^{1}$ Bacharela em Ciências Humanas e graduanda em Ciências Sociais da Universidade Federal de Juiz de Fora (UFJF). Integrante do Núcleo de Pesquisas e Práticas Sociais em Psicologia Social, Políticas Públicas e Saúde (PPS).

${ }^{2}$ Psicóloga e Doutoranda do Programa de Pós-graduação em Psicologia da Universidade Federal de Juiz de Fora- UFJF, na linha de processos psicossociais em saúde. Integrante do Núcleo de Pesquisas e Práticas Sociais em Psicologia Social, Políticas Públicas e Saúde (PPS).

${ }^{3}$ Professora Associada I do Departamento de Psicologia da Universidade Federal de Juiz de Fora, coordena o Núcleo PPS - Núcleo de Pesquisas e Práticas em Psicologia Social Políticas Públicas e Saúde, da Universidade Federal de Juiz de Fora.
}

Vol. 02, N. 01, Jan. - Mar., 2019 - www.revistas.unilab.edu.br/index.php/rebeh 
posição subalterna desses sujeitos, a lógica caritativa que atravessa os serviços de assistência social no município e a falta de conhecimento acerca do gênero enquanto construção social pelos/as profissionais. Além disso, há apontamentos acerca de diferentes modos de subjetivação de tais pessoas, que não se reconhecem nem como transexual nem como travesti.

Palavras-chave: Gênero; Identidades trans; Travesti; População de rua; Assistência Social

\section{Introdução: produzindo sujeitos à margem.}

A formação de identidade do povo brasileiro nos processos de colonização do país

Ao pensar sobre o Brasil atual e estudar os cortes sociais de classe e gênero, é necessário realizar um breve panorama sobre economia, trajetórias e estratégias de poder (FOUCAULT, 2009) que traçaram os processos históricos do país até os dias atuais. É possível identificar, a partir de leituras como Cidadania no Brasil (CARVALHO, 2002), alguns aspectos que marcaram a história do Brasil e que têm se repetido na atualidade, como o recorrente desrespeito ao exercício da cidadania no que diz respeito ao entendimento e ao acesso de cidadãos e cidadãs aos seus direitos. Relativo às sexualidades e aos gêneros, é necessário pensar sua construção não apenas em contextos particulares, mas, sobretudo, é fundamental problematizar como tal construção ocorreu de maneira geral nas sociedades ocidentais (FOUCAULT, 1977; WEEKS, 2000).

Para realizar uma pontual contextualização histórica de alguns dispositivos de poder (FOUCAULT, 2009), expondo brevemente acerca da construção do racismo e das desigualdades sociais no país, parece pertinente retornar a reflexão acerca do Brasil colonial. Constata-se em uma breve digressão histórica que o país sofreu um longo e complexo processo de miscigenação, no qual um dos aspectos deveu-se à necessidade dos colonizadores portugueses em terem de reproduzir para repovoar a colônia, criando assim as possibilidades para ter população suficiente para o trabalho; contando mais do

Vol. 02, N. 01, Jan. - Mar., 2019 - www.revistas.unilab.edu.br/index.php/rebeh 
que efetivamente o ideal romântico da miscigenação, como retratado em obras como Casa Grande \& Senzala, de Gilberto Freyre (2003) e Raízes do Brasil, de Sérgio Buarque de Holanda (1995). Esses autores foram responsáveis pela construção sociológica da identidade do povo brasileiro, tendo impacto até hoje nas políticas públicas para nossa nação (SOUZA, 2017). Vale destacar também que apenas eram considerados cidadãos os homens brancos e cristãos, portanto apenas estes poderiam possuir terra, ter direitos civis e de consumo.

A relação dos portugueses com as mulheres indígenas se dava pouco pelo relacionamento afetivo e muito pelo estupro, e a relação dos portugueses com as mulheres negras apenas pelo estupro (FREYRE, 2003). Os filhos dessas relações, que vão dar o teor de miscigenação para o país, não eram considerados cidadãos. Não eram indígenas, não eram negros e não eram portugueses. Ou seja, desde o processo de formação de identidade da nação brasileira, o próprio povo brasileiro já ocupa, em seu próprio território, uma posição subalterna, fora do padrão, sem direitos civis, sem acesso a terras para produzir ou a condições de vida dignas. Mais que isso, a construção da identidade da nação tupiniquim é atravessada pelo ideário de que o/a brasileiro/a é corrupto/a por natureza, não se esforça e é responsável pela sua posição de miséria, haja vista que os europeus colonizadores (e brancos) são colocados como tendo mais potencialidades para gerenciar nosso país e nossa sociedade (SOUZA, 2017). Se por um lado, os indígenas, africanos, europeus, asiáticos (enfim, os muitos povos que povoaram o Brasil) fazem dele um território multicultural, de mistura linguística e religiosa, por outro lado, a exploração colonial deixou um legado de pobreza e apropriação da flora, dos minérios e riquezas dessas terras, tendo como legado a economia latifundiária de exploração do agronegócio e da monocultura como estratégias econômicas com múltiplos efeitos colaterais. Isso em uma sociedade analfabeta, sem senso de cidadania ou de pátria e à parte de seus direitos civis ou políticos (BUARQUE DE HOLANDA, 1995), que, além disso, teve seu processo de construção de identidade enquanto povo baseado na pretensa verdade de que é um povo desonesto por natureza (SOUZA, 2017).

Esse cenário pode ser compreendido, em partes, devido à importação da modernidade que o país sofreu com a vinda da família real portuguesa para o Brasil (MOREIRA, 2013). Nelson Moreira faz uma diferenciação entre o processo de modernização no que ele vai chamar de modernidades centrais (países em que tal

Vol. 02, N. 01, Jan. - Mar., 2019 - www.revistas.unilab.edu.br/index.php/rebeh 
processo ocorre de forma gradual e por demanda popular) e modernidades periféricas (países em que o processo é importado, imposto pelas autoridades, no qual o Estado está em função do mercado). No primeiro caso, temos, entre outras, uma demanda forte por um senso de igualdade e liberdade individual que está intrinsecamente ligada à política e a formação de valores de uma soberania popular, desenvolvida junto com o capitalismo e depois mais fortemente desenvolvida pelo liberalismo. Entretanto, no segundo caso, esse senso de igualdade não é sequer citado em um primeiro momento de modernização. As questões e demandas populares não são a base que impulsionam a modernização e formação do Estado e da nação. Em um processo contrário, a modernização acontece para reafirmar e proteger privilégios de quem já estava no poder, solidificando a hierarquia política e econômica ao passo em que aliena grande parte da população de seu próprio senso de cidadania, no âmbito individual, e de país como nação e comunidade, no âmbito público.

[...]Assim, retornando-se à realidade pátria, a especificidade do processo de modernização de sociedade da nova periferia, como a brasileira, tem a ver antes com a ausência do que com a presença de uma organização social de uma tradição moral ou religiosa que pudessem, efetivamente, "esquematizar" o impacto modernizante das práticas institucionais transplantadas como "artefatos prontos" (MOREIRA, 2013, p. 192)

Ou seja, podemos perceber que, na realidade brasileira, grande parte da população representada por indivíduos fruto de miscigenação que já ocupavam o papel de subalterno ${ }^{4}$ agora são deslocados para um novo modelo de civilização, moderna, sem consciência ou organização popular. Agravando a isto, dentro da nova esquematização imperial de civilização, não houve distribuição de renda e reforma agrária. O país tornou-se império, porém os sujeitos responsáveis pela economia permaneceram semelhantes em classe socioeconômica, raça e gênero: antes eram os colonizadores, depois os grandes cafeicultores, escravocratas e grandes proprietários de terras. É importante ressaltar também que a cidadania era tão desconhecida pelos brasileiros que até mesmo a chamada "alta sociedade" brasileira da época, os senhores feudais, não conhecia, de fato, a cidadania e seu exercício em sociedade, ainda que possuíssem condições de vida melhores. Eram homens livres para ir e vir, para comprar e para votar,

${ }^{4} \mathrm{O}$ conceito de subalterno trabalhado neste texto segue as teorizações de Spivak (1998). A autora problematiza as relações de poder que produzem a subalternidade como local de fala (e invisibilidade) epistêmica, política e social de algumas parcelas da população.

Vol. 02, N. 01, Jan. - Mar., $2019 \cdot$ www.revistas.unilab.edu.br/index.php/rebeh 
porém, desvinculados de dever cívico para com a sociedade ou do exercício da igualdade entre cidadãos/ãs. Ainda sobre os senhores feudais:

\footnotetext{
Eram simples potentados que absorviam parte das funções do Estado, sobretudo as funções judiciárias. Em suas mãos, a justiça, que, como vimos, é a principal garantia dos direitos civis, tornava-se simples instrumento do poder pessoal. O poder do governo terminava na porteira das grandes fazendas (CARVALHO, 2002, p.).
}

Essa dinâmica e relações de poder e direitos se mantiveram entre a recémformada sociedade brasileira, ponto que, por fugir do escopo central desse artigo, não pretendemos aprofundar. O que vale destacar aqui é que os tensionamentos étnicoraciais e de classe sofreram algumas alterações após a abolição da escravidão no país, caminho que nossa breve digressão histórica pretende discutir.

Abolição da escravatura, processo de urbanização e novas facetas de exclusão

Deslocando nosso recorte histórico para 1888, quando foi finalizada a abolição da escravatura no Brasil (mais por pressão externas do desenvolvimento do capitalismo do que, de fato, por uma questão social, ainda que houvessem muitos movimentos abolicionistas de crítica social no Brasil), sabe-se que não houve grandes mudanças para a população afrodescendente no país, visto que a lei foi promulgada, porém, sem nenhuma política pública para inserção do/a negro/a como cidadão ou cidadã brasileiro/a (CARVALHO, 2002). Expulsos/as das senzalas, as pessoas que foram escravizadas não possuíam casa, não possuíam emprego, estudo ou mesmo condições dignas de vida e muitas vezes até de sobrevivência. Muitos/as deles/as encontraram como recurso a vida nas ruas, alguns continuaram a trabalhar na "casa grande", recebendo menos que o mínimo para se manter dignamente em sociedade. O que impacta em quadros de miséria em todo o país, com crises econômicas e um quadro cada vez mais agravado de pobreza.

Não se pode esquecer da população indígena que, após ser dizimada em quase sua totalidade, encontrava-se sem acesso à terra e a condições de vida; tampouco podese ignorar que a população negra, na história da escravidão no Brasil, foi libertada também às margens da sociedade, excluídos/as da inclusão social e, claro, também vale destacar neste grupo as mulheres que continuavam ocupando a posição de subalternidade em relação os homens (SAFFIOTI, 2004), dentre as quais as negras sofrem uma dupla exclusão: por serem mulheres e negras (DAVIS, 1981/2016). No Brasil, país de uma grande desigualdade econômica, esse processo teve como pano de 
fundo as posições de privilégio dos grandes latifundiários que, ancorados em dogmas religiosos e em velhos costumes, sustentaram concepções acerca dos sujeitos de direito.

Pode-se perceber, nessa breve digressão histórica como se processou o ciclo econômico e político no Brasil colônia, no império e na república, chegando até a ditadura do governo de Getúlio Vargas, já no século XX. Neste sentido, constata-se que parcela significativa da população aqui mencionada: negra, mestiça e mulheres continuaram em posição de subalternidade durante os diferentes percursos históricos do Brasil.

A partir do século $\mathrm{XX}$, com a crescente necessidade de urbanização do país, fomentada pelos interesses econômicos de grandes corporações, o desenvolvimento do capitalismo na Europa e a necessidade de uma produção em grande escala deslocam a população pobre e subalterna de cenário. Acontece no país um processo de urbanização ligado a processos combinados da relação econômica no trabalho e um desenvolvimento das estruturas sociais (VASCONSELOS, 2007). Portanto, desse desenvolvimento das estruturas sociais, nasce uma nova concepção de pobreza no país, corpos subalternos que se deslocam do campo para os centros urbanos buscando melhores condições de vida.

O grande êxodo rural que aconteceu durante a urbanização do país é um fator importante a ser analisado, pois aquelas mesmas pessoas com precária qualidade de vida, de maioria analfabeta, vão para as cidades e centros urbanos à procura de uma possibilidade de renda, emprego e melhoria de vida; em cidades nas quais, na verdade, a demanda era muito maior que a oferta de empregos (NUNES, 2013). Crescendo então novas formas de pobreza, surge no Brasil um novo ator social, a pobreza urbana. Pessoas sem condições de trabalho, em miséria, fome, crianças, negros, mulheres que vão tentando se adaptar à cidade a partir de novos espaços. Como consequência desse processo, destaca-se a eclosão de grandes favelas, e um grande número de pessoas em situação de rua.

Direitos humanos no Brasil, biopoder e sujeitos à margem

É neste cenário que as concepções acerca de direitos humanos no Brasil apresentam algumas nuances. Antes de 1964, os direitos humanos eram atribuídos de modo a estarem vinculados às questões econômicas e de trabalho formal. Dessa maneira,

Vol. 02, N. 01, Jan. - Mar., 2019 - www.revistas.unilab.edu.br/index.php/rebeh 
a vinculação de direitos sociais (e de alguns direitos políticos) estava intimamente ligada à capacidade produtiva da pessoa no mercado formal de trabalho. Durante a ditadura, as mobilizações sociais e seus direitos foram cessados e violados até que, após 1985, passou-se a se discutir novamente a posição de sujeitos de direito. Os direitos violados dentro da ditadura passam ao poder de seu exercício (BOCK, 2010). Contudo, como não houve aprofundamento nessas discussões nesse período, apenas abriu-se espaço para uma concepção neoliberal dos direitos humanos de modo que "o período neoliberal se estende até hoje, e uma de suas faces permite a substituição da noção de direitos pela de oportunidade" (BOCK, 2010, p. 99).

Nesse sentido, deve-se levar em consideração como os direitos humanos no Brasil, muitas vezes, articulam-se com concepções de individualização e culpabilização do indivíduo (SILVEIRA, 2007) por estar na condição em que se encontra, descontextualizando os determinantes sociais, históricos, políticos e simbólicos da pobreza (JR.; XIMENES, 2016). Assim, torna-se pertinente neste texto, como nos estudos destes/as e de outros/as autores/as, reconhecer que "a pessoa em situação de pobreza pode ser abordada como possuidora de uma identidade de oprimido e de explorado que está baseada na sobrevivência, na violência e no medo fruto de uma ordem social opressora" (JR.; XIMENES, 2016, 2016, p. 77).

Além disso, a partir do final do século XIX, com as cidades se desenvolvendo cada vez mais rápido proporcionalmente ao crescimento da pobreza, surge uma nova rede e dispositivos do poder, que operam não apenas no Brasil, mas também em muitos países ocidentais capitalistas, desenvolvendo uma forma de poder que Foucault chama de biopoder, (Foucault, 1987). Percebe-se, no cenário mundial, uma modificação no tipo de poder exercido sobre a população. Pode-se dizer que o que havia antes, nos campos feudais, nos escravocratas e nas colônias, era um tipo de poder que atuava sobre os corpos de forma mais centralizada no que constitui um governo centrado no indivíduo, homem-corpo, a partir de uma técnica de disciplina do trabalho individualizante, restrita e hierárquica. O "soberano" possuía o poder de morte dos indivíduos, em outras palavras, a morte como técnica punitiva e de controle, ou seja, fazerr morrer ou deixar viver.

Na modernidade, o poder não atinge somente o corpo-homem, mas também o corpo espécie (FOUCAULT, 2015). Surge o biopoder, visto que a nova economia exige

Vol. 02, N. 01, Jan. - Mar., $2019 \cdot$ www.revistas.unilab.edu.br/index.php/rebeh 
uma racionalização mais ampla, possui sujeitos livres e, portanto, era necessária uma forma menos onerosa de exercer o poder. Ocorre a transformação de uma disciplina individualizante anatomo-política para uma organização de poder massificante. Surgem novas preocupações, como a natalidade, o problema de morbidade; os principais problemas da morbidade já não são apenas as crises epidêmicas e sim um amontoado de crises endêmicas que vão surgindo, a própria doença surge como fenômeno da população. E então, fazem-se necessárias estimativas, estatísticas, estudos e medições globais para baixar a morbidade, aumentar a produtividade e englobar a vida, visto que no sistema capitalista existem "homens livres" que precisam estar saudáveis para produzir o tempo todo.

A biopolítica vai trabalhar, portanto, a partir de fenômenos ocidentais, as consequências das próprias cidades, essa que vai aos poucos produzindo sujeitos que não se encaixam nas normativas e regulações, que estão fora dos circuitos de produções. A nova forma de organização vai agir sobre a população, sendo esta um problema político, consequência do próprio poder. Nesse domínio de inteligibilidade de fabricação de determinada realidade social e histórica, encontram-se as doenças, a improdutividade, os sujeitos que não produzem, que estão fora dos padrões, os desvios, etc. Dito de outro modo, ocorre a transformação de disciplina para regulamentação; e a morte, que antes era um poder claro do soberano vai, de certa forma, se deslocar para o âmbito privado; morre-se individualmente, e tal morte tem seus cultos, perto de suas famílias. Mas parece explícito também que toda a disciplina sobre o corpo, disciplina do trabalho, não desapareça, que ela se transforme e, da sua junção com a regulamentação, surja a norma. Assim, aqueles que estão fora da norma podem ocupar alguma posição de sujeito invisível nos espaços urbanos, como parece acontecer com a população em situação de rua.

Portanto, se por um lado, a disciplina não se extingue, também não desaparece o poder do soberano de matar. Esse poder é processo constitutivo do Estado e ele o executa de várias formas. Não se manda matar mais, apenas deixa-se morrer a partir de aparatos como, por exemplo, a exclusão e invisibilização em contextos societários e em políticas públicas voltadas para pessoas que estão fora da norma. Novamente, não só no Brasil, mas claramente nesse país, o poder de deixar morrer atua principalmente sobre aqueles que já sofriam há séculos com a exclusão, os negros e pobres. Faz-se operar

Vol. 02, N. 01, Jan. - Mar., 2019 - www.revistas.unilab.edu.br/index.php/rebeh 
aquilo que Foucault (2005) vai denominar "racismo do Estado", posto que essa população antes escravizada agora permanece negligenciada pela nova forma de poder, pois é sobre eles, principalmente, que é exercido o poder de morte, deixando-os à margem da sociedade, sem possibilidade de vida. Nesse contexto, a pobreza e a miséria emergem enquanto únicas condições, demandando perspectivas de pesquisa e atuação ético-política que considerem a constituição social e histórica dessas posições de sujeito, trabalhadas a partir da necessidade de políticas públicas efetivas e de assistência social.

Gêneros e sexualidades dissidentes: outras formas de exclusão

Sendo colonizado por um país cujo um dos objetivos principais era a propagação e expansão da religião católica, deixando grande tradição de conservadorismo, outra população significativamente excluída e oprimida no Brasil é a população pobre LGBTI+. Tratando-se da população $\mathrm{T}^{5}$ em especial (presente na sigla acima), constata-se que não só ocupam posições à margem, até hoje, mas fazem parte também deste corte de exclusão do Estado. Desse modo, a população T é colocada na posição de abjeção. De acordo com Berenice Bento (2017, p. 50), o conceito de abjeção seria:

\footnotetext{
Um conjunto de práticas reativas, hegemonicamente legitimadas, que retira do sujeito qualquer nível de inteligibilidade humana. Os atributos considerados qualificadores para os corpos entrarem no rol de "seres humanos" não encontram morada quando se está diante de uma pessoa na qual o aparato conceitual de que se dispõe para significação da existência humana não alcança. A linguagem entra em pane, em colapso.
}

Nesse sentido, parece pertinente problematizar a questão do gênero, a própria definição contingencial e parcial - do que é um corpo travesti ou transexual e sua posição na produção discursiva de verdades na sociedade brasileira. Pois, para analisar corpos travestis e transexuais em contextos de vulnerabilidade urbana, mais do que uma análise sobre a transição de um corpo feminino para um masculino ou vice e versa, é necessário entender como as perspectivas de gênero binário condicionam uma realidade das

\footnotetext{
${ }^{5}$ Neste artigo, optou-se neste ponto por denominar população $\mathrm{T}$ como uma categoria mais ampla de posições identitárias desviantes da cisgeneridade, tais como travestis e transexuais ou quaisquer corpos dissidentes da coerência socialmente fabricada que designa uma identidade de gênero fixa a partir de determinada configuração específica da matéria, consoante com as problematizações de Butler (2014) acerca da produção dos corpos sexuados.
}

Vol. 02, N. 01, Jan. - Mar., 2019 - www.revistas.unilab.edu.br/index.php/rebeh 
identificações dos corpos, fabricando-os enquanto corpos passíveis de serem lidos na inteligibilidade social engendrada.

O que seria, de fato, o conceito de gênero? Para Butler a definição é muito mais ampla do que um feminino ou um masculino em essência. Conforme a autora:

supor que gênero sempre e exclusivamente significa as matrizes "masculinas"
e "femininas" é perder de vista o ponto crítico de que essa produção coerente
e binária é contingente, que ela teve um custo e que as permutações de gênero
que não se encaixam no binarismo, também são gênero (BUTLER, 2014, p.
253).

Se entendermos o gênero como algo que é socialmente construído, uma norma, é importante esclarecer que não são apenas os indivíduos que tentam chegar mais perto possível do modelo, mas sim um processo contrário no qual o jogo do poder produz os sujeitos, em um campo inteligível, usando como aparato de padronização o binarismo de gênero, que se instituiu na sociedade como verdade universal naturalizada pela anatomia (uma construção discursiva de campos de saber) dos corpos. Esse processo acontece através da repetição que faz funcionar a norma, enquanto é praticada e atualizada na vida em sociedade, nas práticas cotidianas, nos ritos, nas idealizações e nas realizações dos atos e comportamentos, ou seja, naquilo que Butler (2014) definiu como perfomatividade.

A sociedade brasileira teve um processo de colonização conservadora, cristã, de rígida e desigual distribuição de renda, com corte social muito claro e delineado em relação à população negra que vai até o processo de urbanização, gerando grandes focos de pobreza nas cidades. Também devido ao conservadorismo e a forte presença da religião no Estado, o Brasil é um dos países mais violentos com a população LGBTI+ e com alto nível de desigualdade social.

De acordo com os últimos dados do Instituo Brasileiro de Geografia e Estatística (IBGE) divulgadas em 15/12/2017 mais de 50 milhões de brasileiros se encontram a baixo da linha de pobreza extrema, (medida adotada pelo Banco Mundial, em que se define como pobre aqueles/as cuja renda familiar mensal é equivalente a $\mathrm{R} \$ 387,00$ ) o que representa aproximadamente $25,4 \%$ da população brasileira. Não há dados do IBGE sobre as pessoas em situação de rua no Brasil. De acordo com esse instituto, isso ocorre devido à falta de informações domiciliares. Entretanto, atualmente, há pessoas e 
instituições interessadas em conhecer e intervir junto a essa população, desenvolvendo estudos e trabalhos no âmbito das políticas públicas.

Em 2010, foi lançada uma cartilha sobre os direitos dos moradores de rua pelo Ministério Público do Estado de Minas Gerais (MPMG) elaborada por diversas organizações e pastorais de apoio a população em situação de rua para divulgar, conscientizar e explicar sobre a vida e o cotidiano dessa população. Essa população é reconhecida nesse documento como um grupo diversificado de pessoas que estão em situação de miséria, com poucas ou quase nulas condições de alimentação, saneamento básico. Relações com a família interrompida, sem espaço de moradia fixa, dormindo em albergues ou abrigos por algum tempo, em alta situação de vulnerabilidade ${ }^{6}$. Sendo esses paços, os de rua, becos, como os últimos espaços que sobraram para eles na sociedade. Como será abordado adiante, as pessoas travestis e transexuais, em situação de rua, ainda contam com mais agravantes em questões de preconceito e da falta de oportunidades, o que agrava os contextos de vulnerabilidade destas pessoas nas cidades.

Porém, por lei toda cidadã brasileira e todo cidadão brasileiro possui o direito de se estabelecer socialmente, garantia de ascensão e inclusão social a partir da Política Nacional de Assistência Social (PNAS). Baseada nos princípios da Constituição brasileira de 1988, criou-se o tripé que se propõe a garantir por lei a seguridade social com a Previdência Social, Assistência Social e Saúde. De acordo com a Lei Orgânica da Assistência Social (LOAS), criada em 1993, não deve existir qualquer tipo de discriminação, devendo haver respeito à autonomia das pessoas e à sua dignidade. A lei também garante um suporte às pessoas em situação de rua (FREITAS; GUARESCHI, 2014).

Com seu surgimento em 2004, estimulado pelo Ministério Social de Combate à Fome,a PNAS realiza-se de "[...] forma integrada às políticas setoriais e visa a garantir os mínimos sociais, no sentido de proporcionar condições para atender às contingências sociais e à universalização dos direitos sociais" (FREITAS; GUARESCHI, 2014, p.148). Logo em seguida, em 2005, a fím de organizar e criar métodos e modelos de gestão da Assistência Social, é instituído o Sistema Único de Assistência Social, que vai gerir e

\footnotetext{
${ }^{6}$ Utilizamos vulnerabilidade aqui como conceito de vulnerabilidade social, utilizado para designar pessoas ou grupos em situação de ausência de suporte público, laços fragilizados com família, à margem da sociedade, em exclusão (FREITAS \& GUARESCHI, 2014).
}

Vol. 02, N. 01, Jan. - Mar., 2019 - www.revistas.unilab.edu.br/index.php/rebeh 
financiar o funcionamento da PNAS através da articulação com os três níveis de governo: município, estado e União. Cabe, por fim, destacar que a fim de uma maior visibilidade das questões de assistência social, é disponibilizado pelo governo, através do site do Ministério do Desenvolvimento Social, a exposição e a definição dos órgãos de assistência social e suas funcionalidades - que não entraremos em detalhes aqui por fugir do escopo do nosso campo-tema de pesquisa.

Desse modo, buscou-se trazer aqui um recorte bastante pontual, porém pertinente, acerca da construção sócio histórica do gênero e da pobreza no país, materializadas pelas suas margens nas vidas de pessoas transexuais e travestis em situação de rua, de modo que o objetivo da pesquisa aqui relatada, portanto, foi realizar uma análise interseccional entre aspectos e contingências de gênero e classe da população travesti e transexual em situação de rua no município de Juiz de Fora, Minas Gerais. A pesquisa foi realizada durante um ano e se desenvolveu através do uso do método etnográfico em campo nos equipamentos e aparatos de assistência social institucionalizados ${ }^{7}$ da cidade.

\section{Método como esboço da inserção etnográfica: por onde circulam os corpos invisíveis?}

Ao entrar em contato com o campo, percebi que seria necessário um método mais amplo e reflexivo para realização da pesquisa, visto que a efetivação de análise e compreensão só seria possível com a interseccionalidade feminista entre os recortes que emergiam durante as visitas junto à população em situação de rua, e neste contexto, com a população travesti e transexual e suas relações com as instituições de caráter caritativo e de assistência social. Ao longo das visitas, foi possível verificar que havia uma relação direta entre a população em situação de rua e a população travesti e transexual, visto a posição de sujeito que os corpos travestis e transexuais ocupavam naquela situação, seja as vivências nas ruas pela prostituição e única fonte de renda possível, na própria moradia, utilização de drogas (NOGUEIRA, 2012), relações estreitas com a família e a

\footnotetext{
${ }^{7} \mathrm{O}$ uso de assistência social institucionalizada se refere ao processo mais amplo de acesso a instituições, de caráter governamental, filantrópico ou privado, que buscam assistir de alguma maneira a população em situação de rua no nosso município.
}

Vol. 02, N. 01, Jan. - Mar., 2019 - www.revistas.unilab.edu.br/index.php/rebeh 
dependência das instituições caritativas e de assistência social. De certo, foi ao longo do trabalho que se foi tornando cada vez mais necessário utilizar de uma metodologia etnográfica, nos termos de Claudia Fonseca. A partir de uma perspectiva que teria abertura para a interação entre o pesquisador e o objeto de estudo e uma ênfase nas relações cotidianas e no subjetivo (FONSECA, 1998). Pensar desse modo nos aproxima da perspectiva construcionista de ciência, em que negamos o realismo e a base ontológica de verdade dos fatos e, ao invés disso, reiteramos como o fazer ciência é um produto humano e histórico que deve ser socialmente localizado (SPINK, MEDRADO \& MELLO, 2014). Nossas narrativas científicas são, portanto, contingenciais e históricas, de modo a denotar o jogo político de se produzir uma verdade a partir de nossa posição situada (e privilegiada) como membros da academia (HARAWAY, 1995).

Seguindo as pressuposições do construcionismo e suas relações com a linguagem enquanto produtora da realidade (SPINK, MEDRADO \& MELLO, 2014), bem como o caráter qualitativo da nossa abordagem, a etnografia mostrou-se ferramenta rica nesse percurso. A partir da metodologia etnográfica, foi possível analisar as questões de cada informante e as particularidades de seus relatos e vivências para demarcar perspectivas e cortes sociais mais abrangentes e gerais. Já que são as divergências e semelhanças que constroem sutilezas da análise social (FONSECA, 1998). É claro que, não só a partir de uma análise do que era dito pelos/as informantes, foi possível efetuar essa relação entre os indivíduos e as questões mais gerais e sociais, já que, em um método etnográfico, a própria metodologia qualitativa exige para qualquer conclusão a situação em contexto histórico e social das falas e vivências dos/as informantes.

Através dessa ferramenta, foi possível realizar a interseccionalidade feminista entre os cortes sociais apresentados e também a utilização de uma reflexividade feminista no que diz respeito à interação das pesquisadoras com o objeto de pesquisa e uma dinâmica na posição de sujeito acadêmico, visto que sempre existe uma relação de interdependência entre as pessoas que estão participando do processo de investigação (HARAWAY, 1988; NOGUEIRA, 2004). A Reflexividade me auxiliou em alguns pontos muito importantes, como uma autocrítica de meus próprios pensamentos, préconceitos, os entendimentos teóricos e gerais sobre o assunto que eu possuía e a possibilidade de sua interferência ou efeito na pesquisa - todos atravessados pela minha posição enquanto pessoa constituída por diversos marcadores sociais que também

Vol. 02, N. 01, Jan. - Mar., 2019 - www.revistas.unilab.edu.br/index.php/rebeh 
atravessam as pessoas alvo desse estudo (NEVES, 2004). E foi possível certo mapeamento e clareza nos entendimentos sobre as relações de poder, as contingências que atravessam as relações, a posição que eu me encontrava como investigadora, as próprias práticas e conversas com os/as informantes.

Pesquisar no cotidiano, no local de circulação desses corpos abjetos, se mostra uma potente fonte de produção de dados em ciências sociais (SPINK, MEDRADO \& MELLO, 2014). As conversas realizadas no cotidiano das pessoas pesquisadas possibilitam uma produção de sentidos bem próximas dos/as participantes da pesquisa. Desse modo, pesquisar no cotidiano contribui para posicionar as pessoas pesquisadas enquanto protagonistas das verdades fabricadas acerca de si (BATISTA, BERNARDES \& MENEGON, 2014), de modo a minimizar as relações de poder entre as pessoas pesquisadoras e as pesquisadas, possibilitando os subalternos de alguma maneira falarem. Foi adotada no campo a observações do cotidiano devido à possibilidade de compreensão dos sentidos, ou seja, análise do posicionamento dos/as informantes, a partir de suas próprias práticas discursivas (SPINK, 2014). Por exemplo, em conversas mais casuais, pude perceber por muitas vezes formas de tratamento entre eles/as e seu próprio dialeto, de uma forma em que se sentiam mais à vontade para retratar sua própria realidade.

Dessa maneira meu papel como pesquisadora foi de anotar, salvar esses pequenos detalhes para análise, o que Peter Spink (2008) chama de microlugares, que seria uma metáfora para a importância dos acontecimentos cotidianos, dos diálogos, dos acontecimentos abstratos ou não. Ou seja, o método de observação buscou priorizar os acontecimentos, falas, gestos, indicações, demonstrações de sentimentos e práticas do cotidiano para análise do que de fato os informantes estavam passando ou transmitindo, ainda que involuntariamente dentro do seu próprio espaço.

Um dos utensílios mais valiosos para este fim foi a utilização do diário de campo (CARDONA, CORDEIRO \& BRASILINO, 2014): qualquer dado, qualquer informação era importante o suficiente para que fosse anotado e tinha consciência de que seria um possível dado para análise. Levava um caderno e caneta e, com a autorização devida, ia anotando tudo que podia, desde número de contatos com as instituições de caridade até as pausas nas conversas, as emoções tudo que era de expressão dos informantes e até mesmo dos locais.

Vol. 02, N. 01, Jan. - Mar., 2019 - www.revistas.unilab.edu.br/index.php/rebeh 
Sabendo, a partir de uma leitura teórica de Foucault (2009) que cada fala, cada ato ou enunciado era não só uma expressão de sentimentos individuais como também de toda uma construção social e aparatos que atravessam o discurso, ao mesmo passo que tal visão também é trabalhada a partir da análise de dados do método etnográfico, tendo em vista que os dados não falam por si só, são analisados de acordo com as perguntas e motivações que orientam o olhar (FONSECA, 1998). Assim, nos propomos a analisar as verdades construídas aqui através das conversas e observações no cotidiano, materializadas nas nossas pequenas imersões etnográficas ao campo e nos diários elaborados, sob a ótica da análise do discurso de Foucault. Mas antes mostra-se necessário contextualizar quem são as pesquisadoras.

\section{O papel de pesquisadora no campo: aproximações e limitações.}

Foi necessário também me posicionar no papel enquanto pesquisadora lésbica e participante de um grupo de extensão universitária com enfoque em população travesti e transexual. No próprio contato com os/as informantes, é certo que a localização enquanto pesquisadora da universidade já me designava algumas posições de sujeito, e a própria denominação de "pesquisadora" ou mesmo de "estudante universitária" me colocava numa posição de sujeito de saber-poder, o que parecia deixar pouco à vontade os/as informantes. Porém, ao longo da conversa, ao explicar o porquê da visita, a minha participação no projeto ou mesmo da minha inclusão na comunidade LGBTI+ como lésbica, esse deslocamento de posições diminuía e as conversas se tornavam mais abertas, mais esclarecidas e os/as informantes pareciam se sentir com mais liberdade na fala, até mesmo quando havia necessidade de reclamação de algumas instituições ou denúncias de agressões e opressão. O meu posicionamento buscando horizontalidade nas conversas potencializaram as produções de sentidos com foco nas pessoas e suas narrativas. Ainda através de uma reflexividade feminista, foi possível também entender a importância do posicionamento para uma pesquisa, como Haraway (1995, p. 27):

Posicionar-se é, portanto, a prática chave, base do conhecimento organizado em torno das imagens da visão, é como se organiza boa parte do discurso científico e filosófico ocidental. Posicionar-se implica em respnossas práticas capacitadoras. Em consequência, a política e a ética são a base das lutas pela contestação a respeito do que pode ter vigência como conhecimento racional.

Vol. 02, N. 01, Jan. - Mar., 2019 - www.revistas.unilab.edu.br/index.php/rebeh 
Minha participação no campo se deu muito mais através de uma observação flutuante (GOLDMAN, 1995) no sentido em que a pesquisa e análise foram realizadas através de visitas e observação da fala, do comportamento, dos trajetos dos/as informantes. Minha posição como pesquisadora ocorreu em um sentido mais claro de observação, tanto na observação dos/as informantes e participantes da pesquisa quanto das instituições e seus métodos de funcionamento. Durante algumas visitas, era possível identificar posições de sujeito, a forma como as instituições se organizavam, apenas observando e deixando com que eles seguissem sua rotina normalmente. Por isso não se fez necessário visitas diárias, ou até mesmo um acompanhamento incisivo de meses nos locais pesquisados. Visto que a pesquisa foi realizada na cidade em que eu resido e, portanto, o contato com pessoas em situação de rua, travestis e transexuais, ocorre sem maiores dificuldades. Para que eu pudesse realizar essa pesquisa com mais clareza, foi de extrema importância também a minha experiência como voluntária e depois bolsista no grupo de apoio e visibilidade a pessoas travestis e transexuais do município e região ${ }^{8}$. Através desse projeto foi possível realizar um estudo mais aprofundado sobre a população $\mathrm{T}$, assim como acompanhar rodas de conversas com jovens travestis, transexuais e de identidade não-binária, escutar e estudar sobre suas vivências e demandas. Essa aproximação me ver entender as contingências de produção dos corpos dissidentes da cisgeneridade e suas demandas, suas possibilidades de voz e resistência. Tal compreensão me auxiliou no olhar etnográfico do campo, sempre refletindo acerca do privilégio (e poder) que é escrever sobre o outro. Desse modo, problematizamos acerca de quem tem o direito ou privilégio de interpretar a realidade como bússola ética para nossa imersão no campo e nossas construções analíticas.

\section{Encontros com o campo: experiências invisibilizadas, vulnerabilidades (des)localizadas}

A partir das limitações do grupo, em que o público assistido que chegava era atravessado por alguns marcadores sociais de privilégio (pessoas brancas, estudantes de

\footnotetext{
${ }^{8}$ O grupo foi na verdade um projeto de extensão universitária do núcleo de Pesquisas e Práticas Sociais em Psicologia Social, Políticas Públicas e Saúde (PPS), vinculado ao departamento de psicologia da UFJF. O projeto teve como psicóloga voluntária a doutoranda Brune Coelho Brandão e foi coordenado pela professora Juliana Perucchi, da Universidade Federal de Juiz de Fora.
}

Vol. 02, N. 01, Jan. - Mar., 2019 - www.revistas.unilab.edu.br/index.php/rebeh 
colégios particulares, alguns com acesso a plano de saúde, com acesso à universidade), nossas inquietações no trabalho grupal levaram-nos a deslocar nosso olhar para os corpos mais invisíveis dentro da experiência T. Precisávamos então de um ponto de partida para a imersão ao campo. Assim, ficamos sabendo através de um contato com a comissão de Direitos Humanos da Ordem dos Advogados do Brasil (OAB) de um encontro de instituições caritativas voltadas à assistência a população de rua e vimos nesse encontro a possibilidade de um primeiro contato com essas instituições. Considerando que uma abordagem direta a população $\mathrm{T}$ em situação de rua seria invasivo, optamos por iniciar nossos contatos de trabalho através dessas instituições.

O primeiro encontro foi no dia 28 de agosto de 2017, no qual foi realizada uma reunião no instituto $\mathrm{dOAB}$ com a finalidade de montar uma frente única para organização e mobilização de todas as instituições presentes para trabalho em conjunto na assistência à população em situação de rua. Estavam presentes na reunião: advogados da OAB; membros representativos de instituições caritativas de Juiz de Fora que trabalham para melhoria de condição de vida de pessoas em situação de rua, oferecendo refeições, banho, dormitórios e outros serviços de assistência social e também de uma pessoa que já esteve em situação de rua. Nesse encontro, houve relatos dos representantes referente à dificuldade de continuidade nos trabalhos, devido à repressão policial. Considerando a teorização de Foucault (1987) acerca da função da polícia enquanto dispositivo de censura e repressão, vemos operar o racismo de Estado legitimando quais os corpos importam e quais aqueles que devem continuar invisibilizados e violados.

Essa invisibilidade se materializa ainda na crítica geral do contexto de vulnerabilidade das pessoas em situação de rua. A questão da cidadania emergiu como um enunciado que atravessou as reuniões ao serem relatadas histórias de pessoas que não possuem carteira de identidade e tem muita dificuldade para acesso a qualquer serviço público, como por exemplo hospitais. Mais uma vez, se opera a lógica de deixar morrer (Foucault, 2005) ao não possibilitar garantias de existência jurídica materializadas nos documentos, que, conforme os relatos da reunião, se tornam importantes dispositivos de acesso à cidadania. A partir da troca de experiências e conversa, foi criado um grupo virtual, para comunicação geral de todos ali presentes, a fim de facilitar o trabalho de assistência a essa população, caracterizado pelas pessoas ali

Vol. 02, N. 01, Jan. - Mar., $2019 \cdot$ www.revistas.unilab.edu.br/index.php/rebeh 
presentes como "caritativo". Na história da assistência social do nosso país, percebe-se como o caráter caritativo emerge como definição da atuação, de modo a operar uma lógica de favor e não de direitos de fato. Assim, de modo inicial, podemos afirmar que a produção de verdade da prática associada ao adjetivo caritativo faz ver e faz falar acerca do processo de tornar privadas as ações em detrimento de seu caráter público e universal.

Uma fala recorrente entre os presentes que reitera essa postura é a de que: "a cidade é uma cidade caridosa", relacionando a grande quantidade de produtos recebidos em doações e o número expressivo de instituições de 'caridade' como principais atores no processo de assistência à população de rua no município. Foi muito comentado também por todos os representantes presentes sobre a precariedade do serviço prestado da prefeitura, inclusive no principal aparato público de assistência social voltada a essa população na cidade. De acordo com os representantes dessas instituições, assim como as pessoas usuárias com quem conversei em uma instituição de vínculo religioso, as pessoas em situação de rua reclamam bastante em questão de violência e tratamento pelos próprios funcionários que não tem meios e aparatos necessários para dar a assistência social a eles/as. Além disso, nesse momento, estabeleci um vínculo com a diretora de uma fundação de caráter religioso (Instituição $1^{9}$ ) voltada para assistência de pessoas em situação de rua, a senhora Madalena ${ }^{10}$, que se mostrou disposta a realizar conversas comigo e concedeu-me autorização para que eu pudesse frequentar as instituições e entrar em contato com os/as usuários/as.

Em 09 de Setembro de 2017, fui até a principal instituição de assistência citada na reunião (Instituição 2) e também a uma instituição reconhecida na cidade para suporte comunitário (Instituição 3) para obter informações sobre a população T em situação de rua e seu acesso às instituições públicas de assistência social. Em conversa com a Assistente Social da Instituição 2, me foi informado que em média 700 pessoas visitavam o local, entretanto, apenas aproximadamente 10 eram lidas como "travestis" ou "transexuais". Neste momento, percebi em seu relato que a profissional não conseguiu distinguir com clareza a noção de orientação sexual da noção de identidade de gênero.

\footnotetext{
${ }^{9}$ Todos os nomes de instituições citados são fictícios, com finalidade de preservação das entidades.

${ }^{10}$ Todos os nomes citados são fictícios para preservar a identidade das pessoas participantes.
}

Vol. 02, N. 01, Jan. - Mar., 2019 - www.revistas.unilab.edu.br/index.php/rebeh 
A assistente esclareceu que travestis e transexuais eram obrigadas a dormir e conviver nos ambientes destinados ao sexo biológico. Entretanto relatou que as mulheres lésbicas deviam dormir com as mulheres cis. Nesse ponto, percebemos, conforme afirma Butler (2014), como sexo opera em uma lógica de regulação dos corpos, sustentado por um argumento de que o corpo traz uma verdade biológica em si sobre a construção da identidade da pessoa, pois, mesmo uma mulher lésbica sendo uma sexualidade dissidente da heteronorma, ainda sim seu status de mulher é mantido. Tendo em vista esses equívocos, podemos questionar até que ponto ela se refere a uma mulher lésbica não feminina, um homem trans ou uma pessoa de identidade não-binária, visto que sua pressuposição da identidade de gênero das pessoas é construída a partir da leitura dos caracteres sexuais apresentados. Um segmento invisibilizado dentro da população trans os homens trans - em intersecção com a situação de rua pode se potencializar, haja vista que nas produções acadêmicas consultadas, bem como nas observações flutuantes desse trabalho, o léxico rua aparece frequentemente associado à identidade travesti.

Já em contato com a Instituição 3, não foi disponibilizado acesso aos/as usuários/as, visto que foi informado que era necessário ter permissão do órgão, a partir de uma carta solicitante, e passar pela avaliação da instituição. Assim, podemos problematizar as duas vias do processo de burocratização do acesso à instituição. Se, por um lado, a burocratização impede que qualquer pessoa tenha acesso às pessoas participantes, resguardando-as de serem expostas para os mais diversos fins, visto que são pessoas que estão em situação de vulnerabilidade, por outro lado, esse impasse pode proteger as lógicas institucionais de manutenção da posição subalterna das pessoas assistidas.

Devido ao contato com as instituições assistenciais privadas com maior acesso aos usuários e também à população travesti e transexual de rua, optei por manter a observação flutuante nesses espaços. Com base na proposta de produção de sentidos no cotidiano, utilizei como ferramenta metodológica as ferramentas do cotidiano para compreender, através de conversas com os usuários e profissionais dessas instituições, quais as lógicas de organização dos locais e quais as vivências possíveis de serem experienciadas pelos sujeitos.

Em 27 de Novembro de 2017, consegui agendar uma reunião com a diretora da Fundação 1, uma instituição sem fins lucrativos que realiza um trabalho de assistência

Vol. 02, N. 01, Jan. - Mar., 2019 - www.revistas.unilab.edu.br/index.php/rebeh 
social com adultos em situação de rua de Juiz de Fora. Ela definiu os objetivos como ampará-los, promovê-los e inseri-los socialmente. Madalena explicou que todo o material que possui, de roupas, mantimentos, calçados, produtos de higiene pessoal são obtidos através de doação. Mais uma vez, se reitera a ausência de participação do Estado, seja enquanto recursos humanos, seja enquanto investimento financeiro de modo a operar o racismo do Estado (FOUCAULT, 2015).

Expliquei à senhora Madalena sobre o projeto e a pesquisa, a mesma se mostrou interessada não só em disponibilizar o espaço para encontros e rodas de conversas com a população $\mathrm{T}$, como também solicitou palestra e capacitação para os funcionários em questões de gênero e sexualidade, demonstrando ter pouco conhecimento sobre qualquer questão de gênero, materializado em perguntas sobre: o que significa homossexualidade, o que era um gay, uma lésbica, trans, travesti. Percebemos mais uma vez o efeito da abjeção de corpos LGBTI+, visto que enquanto diretora de uma instituição de assistência social designada para pessoas em situação de rua, a senhora Madalena lidava diariamente com uma série de problemas sociais como pobreza extrema, consumo excessivo de álcool e outras drogas, violência, vulnerabilidade social e programática, entretanto não sabia distinguir as categorias políticas e identitárias de lésbica, gay, bissexual, travesti, transexual ou intersexual.

Assim percebe-se uma contraposição entre uma determinada invisibilidade no que diz respeito ao conhecimento e reconhecimento desses corpos enquanto sujeito de direito (BONASSI et al, 2015) ao mesmo tempo em que estão marcados por estarem fora da norma, o que Judith Butler (2014) denomina "corpos abjetos". Corpos que, do ponto de vista ontológico, não existem, não fazem parte da inteligibilidade humana fabricada através da cisnorma, não são considerados seres humanos de fato e de direito:

(...) para ser um sujeito de direitos, merecedor de reconhecimento por parte do Estado é fundamental que se esteja contemplado como um ser humano. É no tocante a condição humana que se reconhece a dimensão inexorável da vulnerabilidade, e, por conseguinte, a necessidade de amparo. (BONASSI, et al, 2015, p. 87).

Os corpos abjetos, por não serem devidamente simbolizados dentro das lógicas institucionais, são alvo de violências simbólicas naturalizadas nas práticas cotidianas. A senhora Madalena explicou-me que a dinâmica com a população T na fundação funciona bem, como relata um exemplo de um dos serviços disponibilizados na instituição, o de

Vol. 02, N. 01, Jan. - Mar., 2019 - www.revistas.unilab.edu.br/index.php/rebeh 
espaços reservados para banho dos usuários, o qual tem um dia específico de banho para homens e um diferente para mulheres. De acordo com ela, algumas travestis pediram a organização da instituição para tomar banho no dia referente ao seu gênero devido à hostilização que acontecia no banheiro masculino por parte dos usuários homens, ao constrangimento e à necessidade de adquirir roupas femininas, pois as roupas são disponibilizadas logo após o banho. A solicitação foi aceita pela organização, porém algumas mulheres cis se sentiram desconfortáveis com a situação. Perante a isso, a organização abriu o banheiro masculino no dia do banho feminino, e as travestis tomam banho juntas no banheiro masculino, havendo dias em que todas tomam banhos juntas normalmente também, mulheres travestis e cisgêneras.

Observamos então a construção simbólica de um "terceiro banheiro", o banheiro designado exclusivamente para mulheres travestis e transexuais. A lógica deste terceiro banheiro opera a partir de uma violência simbólica institucional regulada pela norma cisgênera que ocorre cotidianamente na vida da população $\mathrm{T}$, de forma que existe $\mathrm{o}$ banheiro feminino como um direito das mulheres cis, e outro banheiro designado para mulheres travestis e transexuais como uma concessão ou barganha para esses corpos. $\mathrm{Ou}$ seja, mais uma vez a abjeção desses corpos se relaciona diretamente com o seu direito de uso do aparato público institucional. Isso nos traz o questionamento de onde e quando esses corpos abjetos podem circular e quem é que designa esse espaço. Desse modo, há a intersecção de vulnerabilidades, localizadas de acordo com os diferentes marcadores sociais que produzem os corpos enquanto sujeitos viáveis no mundo.

A partir desse contato, agendamos uma reunião com os/as usuários/as, que ocorreu no dia 14 de Novembro de 2017 na Fundação 1. A proposta foi uma roda de conversa aberta, para que os/as usuários/as se sentissem a vontade para falar sobre suas vivências, explicar suas relações com os órgãos públicos da cidade e seu cotidiano. Foram apenas 3 moradores de rua. Joaninha ${ }^{11}$, que possui 29 anos, falou sobre sua identificação. Não se reconhece como travesti ou transexual, diz não entender muito bem como isso funciona. "Sou viado, é o que eu sou. Bicha mesmo. Me visto de mulher, pinto minhas unhas e gosto do meu apelido feminino. Sou viado e usuário de crack."

${ }^{11}$ A referida pessoa em questão se identifica como identidade de gênero mais fluida, que joga com a linguagem e as vestimentas binárias. O nome com a qual se identifica representa o diminutivo de um substantivo que designa um animal. Portanto, para preservar o sigilo dessa pessoa, foi alterado para um léxico que mantivesse as suas características semânticas e estruturais do nome original.

Vol. 02, N. 01, Jan. - Mar., 2019 - www.revistas.unilab.edu.br/index.php/rebeh 
Através da manutenção do léxico 'viado' em sua fala, percebe-se como ela encontra um modo confortável para nomear seu processo de subjetivação dentro dos jogos discursivos de poder da fabricação dos gêneros elegíveis enquanto legítimos. O poder das regulações de gênero possibilita processos de sujeição (BUTLER, 2017), como as identidades forjadas do binarismo, mas também processos de resistência (BUTLER, 2017) semântica desses corpos através da manipulação gramatical da língua binária (PERES, 2012). Nesse ponto, percebemos como a linguagem possibilita formas materiais de resistência frente à verdade fabricada de que características corporais definem posições indenitárias. Por isso, há deslocamentos no uso do corpo, tais como pintar as unhas e usar "roupas de mulher".

Vale destacar ainda como Joaninha também se subjetiva através da enunciação usuário de crack, algo que se repete nas falas das demais pessoas presentes. Assim, em relação à prostituição e uso de drogas, perante o depoimento dos/as usuários/as, os dois parecem estar diretamente ligados às pessoas não-cis em situação de rua, mas não apenas pela questão de gênero. O uso de drogas, conforme literatura na área (CUTULI, 2015; DUQUE, 2003; ROCHA GODOY, 2013; NOGUEIRA, 2012), está ligado a maior parte da população de rua em geral, devido a situações precárias de vida, falta de suporte, assistência social e política pública e o trabalho com a prostituição. Podemos perceber como o crack se torna dispositivo de designação de posições de sujeito dessas pessoas e como esse processo de autonomeação impacta em seus processos de subjetivação enquanto se tornar sujeitos, e, mais ainda, sujeitos de direito.

De acordo com o relato dos/as usuários/as, a prostituição é o melhor, se não o único meio, das travestis e transexuais em situação de rua conseguirem dinheiro. Esse modo de subsistência coloca as pessoas em situação de vulnerabilidade, haja vista que houve relatos sobre problemas como abuso do cliente, não pagamento do serviço prestado, agressão física dos clientes e também da polícia: “Às vezes a gente tava(sic) lá, porque tem que ficar no escuro né, a gente não vai botar a cara no centro duas horas da tarde pra trabalhar, eu não tenho coragem... aí fíca no escuro esperando o cliente e a polícia não quer saber de nada, acha que é droga, que é assalto, qualquer coisa assim e desce a porrada. Já apanhei muito. E as mulheres, elas ficam lá pelo dinheiro mesmo, sabe? Seja pra comprar droga, alimentação ou uma maquiagem”. Dentro desse relato, podemos observar variadas formas de violência, seja com a população de rua em geral,

Vol. 02, N. 01, Jan. - Mar., 2019 - www.revistas.unilab.edu.br/index.php/rebeh 
seja contra as mulheres cis e travestis. Referente aos corpos não cis, pode-se observar a violência exercida no que diz respeito a uma marca e depreciação do próprio corpo e de sua associação com o trabalho de prostituição, ao relatar agressões não apenas da população em geral ou dos clientes, mas também uma agressão física da polícia.

A polícia atua como dispositivo moralizador dos corpos e práticas, executando a função de vigiar e punir as pessoas que fujam às normas - neste caso, normas rígidas de gênero e de classe, haja vista que corpos não produtivos acabam por ser marginalizados e tendo seus direitos negados. Esse corpo, por ser abjeto, fica suscetível a vários processos de interpretação, podendo se interseccionar com contingências como estar em situação de rua, prostituição, uso ou venda de drogas ilegais, o que potencializa sua vulnerabilidade e possibilita o acontecimento de variados atos violentos vindos de diferentes posições de sujeito. Importante ressaltar também que mais uma vez opera o racismo de Estado (FOUCAULT, 2005), visto que não há nenhum órgão regulador para o trabalho de prostituição, assim como também não há nenhuma assistência ou segurança pra essas mulheres - sejam cis, travestis ou trans. Pelo contrário, vemos operar mais do que a lógica do deixar morrer, opera também a lógica do soberano que de fato usa de agressões físicas para com esses corpos como métodos de higienização dos espaços urbanos e de restrição de espaços em qual esses corpos podem circular.

Referente ao uso das instituições caritativas e da prefeitura, as participantes disseram que a situação era muito pior na Instituição 2 (uma instituição pública), por exemplo, que qualquer homossexual ou travesti era muito hostilizado/a na instituição e apanhavam muito. Após a separação das casas de acolhimento em femininos e masculinos isso melhorou. "A Instituição 1 era um lugar sem lei, agressão sem vistoria”, explicam as participantes. Aqui tratamos de um viés diferente do anterior, visto que se trata de um aparato institucional do Estado, em que, de acordo com os/as usuários/as ocorria "agressão sem vistoria". Cabe o questionamento de quem eram esses corpos que estavam sendo agredidos? De que forma essas agressões ocorriam e porque elas melhoraram muito após a separação de gênero? Até onde a lei opera e a serviço de quem?

Vemos, portanto, que quando se trata de instituições em que o discurso é caritativo e não do Estado, as coisas acontecem de forma menos violenta, visto que, nesses casos, os/as próprios/as usuários/as não estão em posição de sujeito de direito, e

Vol. 02, N. 01, Jan. - Mar., 2019 - www.revistas.unilab.edu.br/index.php/rebeh 
sim de quem recebe caridade e os sujeitos que operam e fazem funcionar esses locais são voluntários, que estão exercendo essa caridade. Por outro lado, quando se trata de locais institucionais em que as pessoas que operam e organizam esses espaços são funcionários públicos e que a sua posição de sujeito é de representante do Estado, a violência é maior. É possível analisar isso mais uma vez através do Racismo de Estado (FOUCAULT, 2005 ) e do próprio conceito de corpo abjeto (BUTLER, 2014), pois ao mesmo tempo em que o Estado cria aparatos que em teoria são para auxiliar a ascensão e inclusão social das pessoas em situação de rua, esse mesmo Estado não capacita os funcionários ou cria mecanismos para lidar com esses corpos abjetos ou fazer com que deixem de ser abjetos. Dessa maneira, fez-se necessário a separação de espaços designados para gênero, entretanto apenas os corpos cis têm esse direito, corpos travestis e transexuais continuam abjetos e sem amparo institucional para ocupar sua posição de sujeito de direito. Dois meses após a aprovação desse artigo, tivemos notícia de que as casas de passagem femininas começaram a acolher mulheres travestis e transexuais, sendo que tivemos um convite para mediar as relações e aceitação dessas mulheres nesse espaço. Um trabalho de entendimento das vivências travestis e transexuais está sendo construído coletivamente por nós lá.

No que diz respeito à saúde mental não só da população $\mathrm{T}$, mas de toda população LGBTI+ em variados níveis de vulnerabilidade, podemos verificar que apesar de ser notada uma melhoria nas diretrizes de direitos humanos ou até mesmo em questões de visibilidade em propagandas, exibições em televisões, novelas e na mídia em geral, a resposta contrária tem crescido na mesma proporção. Ou seja, ainda que parte da população esteja apta a aceitar e entender as demandas LGBT, a intolerância e agressão a essa população tem crescido com os setores conservadores (OLIVEIRA DUARTE, 2011). Ao passo em que o conflito entre sujeitos LGBTI+ que assumem sua identidade e ocupam espaço de resistência aumenta cada vez mais com setores conservadores e resultam também em uma maior agressão à comunidade como um todo. Segundo o Grupo Gay da Bahia ${ }^{12}$, entre 2016 e 2017 foi registrado o aumento de $30 \%$ de assassinato da população LGBTI+, ainda segundo este levantamento foi registrado que a

\footnotetext{
${ }^{12}$ Segundo dados recuperados do seguinte sítio: https://oglobo.globo.com/sociedade/assassinatos-de-lgbtcrescem-30-entre-2016-2017-segundo-relatorio-22295785
}

Vol. 02, N. 01, Jan. - Mar., 2019 - www.revistas.unilab.edu.br/index.php/rebeh 
cada $19 \mathrm{~h}$ um LGBT é assassinado ou comete ato de autoextermínio. Dentre os assassinatos, a maior parte ocorre com armas de fogo.

Portanto, fazendo recorte de classe, cor, gênero e sexualidade, vemos que a população $\mathrm{T}$ em situação de rua segue ocupando espaço de maior vulnerabilidade e por consequência com maior necessidade de amparo Estatal e de políticas públicas que reconheçam esses sujeitos como sujeitos de direito e que insiram esses corpos dentro da sociedade com possibilidades reais de acesso a saúde, educação, emprego, e etc. Entretanto, vemos que não só a população T, mas como toda a população LGBTI+ necessita ainda de um amparo público no que diz respeito à saúde mental. Visto os dados apresentados acima e as problemáticas de segurança e de saúde mental que a população sofre todos os dias, se faz necessário não só uma política pública efetiva que reconheça a população LGBTI+ e lhe assegure direitos civis e humanos, como também, um programa que de fato dê suporte psíquico a esses sujeitos que vem ocupando há muito temo a margem da sociedade. Reiterando que por mais que se reconheça os “avanços” de níveis sociais e mediáticos de visibilidade LGBTI+, se faz necessário mais do que isso. Para que seja alcançado de fato todo esse grupo, é imprescindível a interseção entre a pauta identitária e o recorte de classe para que assim sejam realizadas políticas públicas efetivas que reconheçam todos os corpos em suas posições de vulnerabilidade social e psíquica, tendo como objetivo o reconhecimento do Estado desses corpos como sujeito de direito e fornecendo suporte psíquico e social para que os mesmos também se reconheçam de tal maneira.

\section{Considerações finais: demarcações de corpos e limites de acesso à assistência social.}

A partir dos dados analisados, vemos o quão abrangente é falar sobre pessoas em situação de rua e a população T. Percebemos que mesmo quando tentamos estudar essa população, alguns corpos continuam invisibilizados e ausentes, no campo e até mesmo em estudos e materiais analisados, como por exemplo os homens trans. Vimos que com frequência são realizados estudos sobre mulheres travestis e transexuais em situação de rua, seja por falta de moradia ou pela prostituição, porém há muito a ser analisado sobre homens trans, suas vivências e principalmente onde esses corpos circulam em situação de rua.

Vol. 02, N. 01, Jan. - Mar., 2019 - www.revistas.unilab.edu.br/index.php/rebeh 
A partir de uma pequena imersão etnográfica tentamos entender a complexidade da circulação da população $\mathrm{T}$ em situação de rua e suas relações com os aparatos institucionais da cidade. Entretanto, entendemos que realizamos uma pesquisa de campo pontual, e que é necessário um trabalho mais amplo para dar maior complexidade e abrangência a essas relações. Seria necessário um trabalho mais aprofundado para detalhar com maior clareza sobre as formas de funcionalidade das instituições, os seus mecanismos de funcionamento e obtendo esses dados, realizar estudos mais aprofundados, mapear a circulação desses corpos, com finalidade de pensar novas políticas públicas que consigam de fato atender a essa população e colocar esses corpos na posição de sujeito de direitos.

Entendemos também que há a necessidade de uma pesquisa mais ampla para estudar até mesmo a forma de subjetividade desses corpos: como se entendem e se colocam em posição a sua sexualidade e seu gênero, as relações com o uso de drogas e as posições que ocupam perante aparatos de repressão do Estado. Visto que, neste trabalho, a partir de uma pequena pesquisa etnográfica, tentamos realizar uma intersecção entre a população travesti e transexual, pessoas em situação de rua e a rede de assistência social municipal. Desse modo, nosso objetivo foi entender a complexidade que isso possui dentro da cidade e, a partir disso, pontuar os enfoques de vulnerabilidade e a necessidade de maiores estudos sobre as questões de gênero, no que diz respeito a própria subjetividade desses sujeitos, aos aparatos institucionais de assistência social e a realidade da população em situação de rua.

Por fim, cabe ressaltar alguns desdobramentos práticos dessa pesquisa. Em maio de 2019, a convite de uma instituição vinculada à Secretaria de Desenvolvimento e Proteção Social do município, uma das autoras do artigo realizou uma capacitação com profissionais da rede de assistência social local, aberta também ao público geral, vide notícia no site da prefeitura municipal ${ }^{13}$. A atividade se dividiu em um encontro de três horas, replicado no dia seguinte para atingir todos/as os/as funcionários/as da rede. Cada encontro contou com aproximadamente trinta profissionais, atingindo em média sessenta pessoas que estão inseridas nas casas de passagem, abordagem social, CREPOP, serviços de saúde pública e instituições de acolhimento a pessoas em situação de

\footnotetext{
${ }^{13}$ A divulgação dessa ação pode ser acompanhada segundo o link do site da prefeitura: https://www.pjf.mg.gov.br/noticias/view.php?modo=link2\&idnoticia2=64279
}

Vol. 02, N. 01, Jan. - Mar., 2019 - www.revistas.unilab.edu.br/index.php/rebeh 
vulnerabilidade social. Trabalhou-se com conceitos sobre gênero, sexualidade e população LGBTI+ através da desconstrução dos saberes dos/as participantes, possibilitando a reflexão acerca de uma prática mais humanizada no que concerne aos gêneros e sexualidades dissidentes que compõe a população em situação de rua em Juiz de Fora, MG. O intuito é que essas ações educativas tenham continuidade ao longo do ano.

\section{REFERÊNCIAS}

BENTO, Berenice.Transviad@s, gênero sexualidade e direitos humanos. Salvador: EDUFBA, 2017.

BOCK, Ana Mercês Bahia. Direitos Humanos no Ensino de Psicologia. São Paulo, Programa de Pós graduação em psicologia da educação Universidade Católica de São Paulo. 2019.

BONASSI, Bruna Camillo et al. Vulnerabilidades mapeadas, Violências localizadas: Experiências de pessoas travestis e transexuais no Brasil. Quaderns de Psicologia volume 17, número 3, 83-98, 2015.

BUARQUE DE HOLANDA, Sérgio. Raízes do Brasil. 26a Ed. São Paulo: Companhia das Letras, 1995.

BUTLER, Judith. A vida psíquica do poder: teorias da sujeição [trad. Rogério Bettoni]. Belo Horizonte: Autêntica, 2017.

BUTLER, Judith. Regulações de Gênero. Cadernos pagu, (42,), janeiro-junho de 2014: p. 249-274, 2014.

CARDONA, M. G., CORDEIRO, R. M., \& BRASILINO, J. A Produção de informação na pesquisa social: Observação no cotidiano: um modo de fazer pesquisa em psicologia social. Em: SPINK, M. J., BRIGADÃO, J., NASCIMENTO, V., \& CORDEIRO, M (Orgs.). A Produção de informação na pesquisa social (pp. 123-149). Rio de Janeiro: Centro Edelstein de Pesquisa Sociais, 2014.

CARVALHO, José Murilo de. Cidadania no Brasil: o longo Caminho. $3^{\mathrm{a}}$ ed. Rio de Janeiro: Civilização Brasileira, 2002.

CUTULI, Mariá Soledad. Travesti associations, states policies, and NGOS: Resistance and collective action in Buenos Aires, Argentina. Sexualities, volume 18, número 3, p. 297-309, 2015.

Vol. 02, N. 01, Jan. - Mar., 2019 - www.revistas.unilab.edu.br/index.php/rebeh 
DAVIS, Angela. Mulheres, raça e classe. Trad. Heci Regina Candiani. 1ed. São Paulo: Boitempo, 1981/2016.

DUARTE, Marcos Jose de Oliveira. Diversidade sexual e Política Nacional de Saúde Mental: contribuições pertinentes dos sujeitos insistentes. Rio de Janeiro, Em Pauta, 2011.

DUQUE, Thiago. Reflexões Teóricas, Políticas e Metodológicas Sobre um Morrer, Virar e Nascer Travesti na Adolescência. Revista Estudos Feministas, 2003.

FONSECA, Claudia. Quando cada caso NÃO é um caso. Caxambu: Universidade Federal do Rio grande do Sul, 1998.

FOUCAULT, M. História da Sexualidade I: a vontade de saber. Trad. M.T. C. Albuquerque e J. A G. Albuquerque. Rio de Janeiro: Graal, 1977.

FOUCAULT, Michel. Arqueologia do Saber. $7^{\text {a }}$ Ed. Rio de Janeiro: Forense Universitária, 2009.

FOUCAULT, Michel. Aula de 17 de março de 1976. In: Em defesa da sociedade. São Paulo: Martins Fontes, p.285-31. 2005.

FOUCAULT, Michel. Vigiar e Punir: nascimento da prisão. Trad. Lígia M. Ponde Vassalo. Petrópolis: Vozes, 1987.

FREITAS, Cristiane Redin; GUARESCHI, Pedrinho A. A assistência social no brasil e os usuários: possibilidades e contradições. UNILASALLE, Canoas, número. 25, abr. 2014.

FREYRE, Gilberto. Casa Grande \& Senzala. 48 Ed. Recife: Global Editora, 2003.

GOLDMAN, Márcio. Antropologia contemporânea, sociedades complexas e outras questões. Rio de Janeiro, Anuário Antropológico/93, 1995.

HARAWAY, Donna. Saberes localizados: a questão da ciência para o feminismo e o privilégio da perspectiva parcial. Cadernos Pagu, número. 5, 1995.

JR., James Ferreira Moura; XIMENES, Verônica Morais. A identidade social estigmatizada de pobre: uma constituição opressora. Fractal: Revista de Psicologia, volume 28, número. 1, p. 76-83, 2016.

Ministério do Desenvolvimento Social, 08/2015. Site do Ministério do Desenvolvimento Social. Disponível em: http://mds.gov.br/assuntos/assistencia-social/o-que-e

MOREIRA, Camatta Nelson. Aspectos históricos da construção da sub(cidadania) no brasil: o tortuoso percurso do estado social e os desafios do (jovem) constitucionalismo dirigente em "terrae brasilis". Revista Brasileira de Direito, volume 9, 2013.

Vol. 02, N. 01, Jan. - Mar., 2019 - www.revistas.unilab.edu.br/index.php/rebeh 
NEVES, Sofia. Metodologia Feministas: A Reflexividade ao serviço da Investigação nas Ciências Sociais. V Congresso Português de Sociologia, Sociedades Contemporâneas: 2004.

NOGUEIRA, Conceição. Contribuições do construcionismo social a uma nova psicologia do gênero. Cadernos de Pesquisa, número 112, p. 137-153, 2001.

NUNES, Rodrigo dos Santos. A Relação Entre Sujeitos em Situação de Rua e o Poder Local: protagonismo ou passividade? Dissertação (Mestrado no Programa de Pós Graduação em Serviço Social) - Porto Alegre, 2013.

PERES, William S. Travestilidades nômades: a explosão dos binarismos e a emergência queering. Estudos Feministas, volume 20, número 2, p. 539-547, 2012.

ROCHA, Rita Martins Godoy; PEREIRA, Débora Leticia; DIAS, Thaísa Magna. O contexto do uso de drogas entre travestis profissionais do sexo. Saúde Soc., São Paulo, volume 22, número 2, p.554-565, 2013.

SAFFIOTI, Helena I. B. Contribuições feministas para o estudo da violência de gênero. Cadernos Pagu, número 16, p. 115-136, 2001.

SILVEIRA, Andrea Fernanda. Caderno de psicologia e políticas públicas. Curitiba: Gráfica e Editora Unificado, 2007.

SOUZA NOGUEIRA, Francisco Jander de. "Trabalhadas no feminino": um estudo sobre corpo, desejo e prostituição travesti em Fortaleza- CE. Revista Latino-americana de Estudo sobre Cuerpo, Emociones y Sociedaded, número 8, 2012.

SOUZA, Jessé. A elite do atraso: da escravidão à Lava-Jato. Rio de Janeiro: Leya, 2017.

SPINK, Mary Jane.; MEDRADO, Benedito \& MELLO, R. P. Vinte e cinco anos nos rastros, trilas e riscos de produções acadêmicas situadas. Em: Spink; Brigadão; Nascimento; Cordeiro (org). A produção de informação na pesquisa social: compartilhando ferramentas. Rio de Janeiro: Centro Edelstein, 2014.

SPINK, Peter. O pesquisador conversador no cotidiano. Psicologia \& Sociedade, número 20, p. 70-77, 2008.

SPIVAK, Gayatri Chakravorty. Pode o subalterno falar? Belho Horizonte: Editora UFMG, 2010.

VASCONCELOS, E. M. Saúde Mental e Serviço Social: o desafio da subjetividade e da Interdisciplinaridade. Editora: Cortez, 2013.

WEEKS, Jeffrey. O Corpo e a Sexualidade. $2^{\text {a }}$ Ed. Belo Horizonte: Autêntica, 2000.

Vol. 02, N. 01, Jan. - Mar., 2019 - www.revistas.unilab.edu.br/index.php/rebeh 


\title{
Where circulate the invisible bodies? Intersections between homeless people and dissident gender in urban instituicional acess
}

\begin{abstract}
In Brazil, historically the black and indigenous population suffered violence that placed them in a position of subalternity, in order to produce different positions of subjects of (without) right. In the present day, this historical, political and social process made possible, through the notion of neoliberal law in the country during the period of redemocratization, that these people historically the margin occupied a new position of subject - that of population in a homeless situation. In addition, Brazil is the country with a high rate of violence against the travesti and transsexual population. Thus, this work, based on the feminist intersectional perspective, aims to articulate class, race and gender markers in order to problematize the limitations of the institutional accesses that homeless travesti and transsexual people experience in the city. We made a floating observation, according to the presuppositions of ethnography, in the institutions in which such subjects moved in the city. Through this, a field diary with impressions and speeches was elaborated, analyzed from the methodological point of view of Foucault's discourse analysis. As a result, it is possible to emphasize the normative and repressive role of the police in reiterating their subordinate position, the charitable logic that crosses the services of social assistance in the city and the lack of knowledge about the gender as a social construction by the professionals. In addition, there are notes about different ways of subjectivation of such people, who do not recognize themselves neither as transsexual nor as travesti.
\end{abstract}

Keywords: Gender; Trans Identity; Travesti; Homeless People; Social Assistence

Recebido em: 02/02/2019

Aceito em: 12/04/2019

Vol. 02, N. 01, Jan. - Mar., 2019 - www.revistas.unilab.edu.br/index.php/rebeh 